\title{
Une idée simple, une application, des vies sauvées
}

\author{
Jocelyn Corniche \\ Dr, Chef de clinique Service d'anesthésiologie et des urgences, CHUV Lausanne
}

Tout commence après une longue nuit de garde. Je suis en charge d'un jeune homme qui a subi un traumatisme cranio-cérébral sévère il y a une semaine suite à un accident de la route. La situation est dépassée et il vient d'être déclaré cliniquement mort. Sa famille et ses parents sont à ses côtés, inconsolables.

Le plus dur reste à venir car ils doivent répondre à une question difficile: est-ce que leur fils est donneur d'organes? La vérité est qu'ils n'en savent rien car ils n'ont jamais abordé le sujet: leur fils était jeune et en bonne santé. Nous regardons alors dans ses affaires à la recherche d'une carte de donneur d'organes mais nous n'en trouvons pas.

La décision est alors beaucoup trop difficile à prendre pour la famille et elle décide finalement de ne rien faire: leur fils ne donnera pas ses organes.

Ceci est un problème majeur en Suisse. Quand la volonté du patient n'est pas connue, le personnel médical s'adresse en général à la famille. Et elle refuse la plupart du temps car c'est le moment le moins opportun pour prendre une décision aussi grave. Je quitte donc l'hôpital, fatigué et frustré, et regagne mon domicile pour me reposer. Quelques heures plus tard, je me réveille et j'ai besoin de me changer les idées. Je décide d'aller faire quelques courses et me rends dans un grand magasin de meubles suédois pas loin de chez moi. Arrivé à la caisse, je présente ma carte de fidélité sur mon smartphone puis je paie. Nous avons des amis qui viennent dîner le soir et je dois encore faire quelques achats. A la caisse du supermarché, j'affiche à nouveau ma

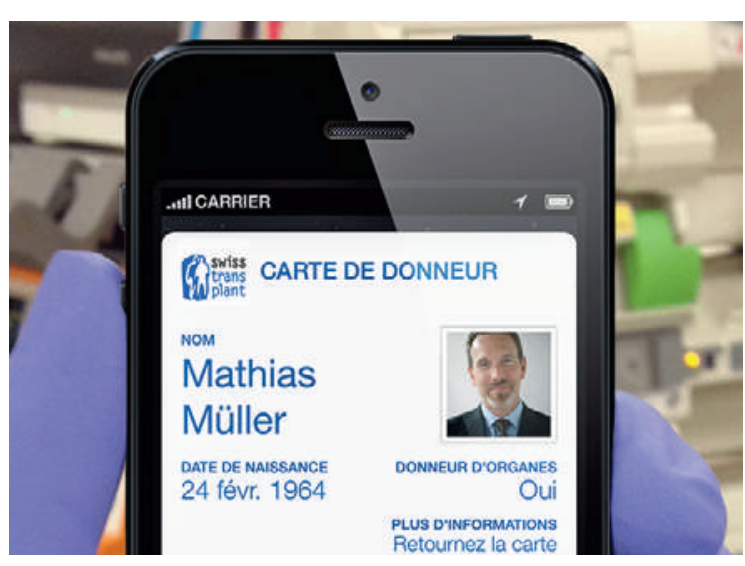

carte client sur mon smartphone avant de payer. De retour à la maison, je m'assieds dans mon salon, me remémore la situation de la nuit précédente à l'hôpital et une idée commence à germer...

Un mois plus tard, tout est sur papier: une carte de donneur d'organes numérique que l'on pourra installer sur son téléphone. Je présente le projet au président de la fondation Swisstransplant qui m'encourage à le réaliser.

Après quelques semaines seulement, j’ai déjà un prototype qui fonctionne et le montre très fièrement à un de mes amis. Il me dit: "Super, excellente idée, mais comment est-ce que l'on accède à la carte quand le téléphone est bloqué...?»

Je réalise à cet instant que tout mon projet est en train de s'effondrer: ma carte de donneur d'organes sera inaccessible à l'hôpital car le téléphone sera très probablement verrouillé avec un code.

\section{Installez votre carte de donneur d'organes} électronique Swisstransplant en téléchargeant l'application Echo112 ou en visitant www.emergencyID.ch

La nuit suivante, je me souviens avoir lu un article sur une nouvelle technologie: une balise Bluetooth capable d'interagir avec les smartphones, même lorsqu'ils sont verrouillés. Je réussi à m’en procurer un exemplaire et découvre avec enthousiasme que cela fonctionne comme prévu: la carte de donneur d'organes s'affiche automatiquement lorsque le téléphone détecte la balise. Il ne reste plus qu'à convaincre les hôpitaux d'installer ces balises dans leur salles d'urgences, ce qui prend un peu plus de temps que prévu car cette technologie est nouvelle et la plupart n'en ont jamais entendu parler. Mais avec un peu de persévérance et quelques explications, la majorité des hôpitaux comprend le potentiel du projet et accepte d'installer ces balises. Actuellement, seulement deux mois après le lancement de la carte de donneur d'organes électronique, plus de 50000 suisses l'ont déjà téléchargée et ce chiffre continue d'augmenter chaque jour. Une idée simple, une application et quelques personnes qui croient en votre projet permettent parfois de réellement faire changer les choses. 